\title{
Analysis on Intellectual Property Management of Construction Enterprises
}

\author{
Yuanxiang Jian* \\ China First Metallurgical Group Co., Ltd., China \\ *Corresponding author: Yuanxiang Jian, 272609340@qq.com
}

\begin{abstract}
As the main force of construction enterprises, construction enterprises shoulder the important task of national pillar industries. However, at present, construction enterprises are still labor-intensive enterprises, with low profitability, low overall scientific and technological level, insufficient innovation ability and weak application and protection of intellectual property rights. Based on the current situation of construction enterprises, combined with the author's enterprise, this paper considers the problems existing in the intellectual property management of construction enterprises, and puts forward some countermeasures for the intellectual property management.
\end{abstract}

Keywords: Construction enterprise; Intellectual property management; Current situation and countermeasures

Publication date: September 2021; Online publication: September 30, 2021

\section{Introduction}

Intellectual property rights are the exclusive rights legally enjoyed by people with respect to the product of their intellectual labor, which is usually the exclusive or sole right granted by the state to the creator for his intellectual achievements in a certain period of time, and is the property right enjoyed by the right holder for the achievements created by his intellectual labor. Generally, it is only valid in a limited period of time. Intellectual property rights generally include copyright (copyright), patent right, trademark right, right of discovery, right of invention and other scientific and technological achievements. Intellectual property management refers to a systematic project including a series of management behaviors such as intellectual property strategy formulation, system design, process monitoring, application and implementation, personnel training, innovation and integration. From the perspective of enterprise management, the generation, implementation and protection of enterprise intellectual property are inseparable from the effective management of intellectual property.

\section{Importance of intellectual property management of construction enterprises}

With regard to intellectual property management, China attached great importance to and established the State Intellectual Property Office to specialize in national intellectual property management. In recent decades, it has been proposed to improve the intellectual property protection system since the 16th CPC National Congress, to implement the intellectual property strategy again at the 17th CPC National Congress, and to implement the innovation driven development strategy at the 18th CPC National Congress, It shows that the state attaches great importance to intellectual property rights; The GB/T 29490-2013 Enterprise Intellectual Property Management Code, which came into effect on March 1, 2013, is the first national standard for enterprise intellectual property management in China. It is a normative document guiding enterprises to plan, implement, inspect and improve the intellectual property management system, and has opened a new voyage for enterprise intellectual property management in China.

As a pillar industry in China, construction industry plays an important role in economic construction. 
Construction enterprises with many employees and a high proportion of completed construction output value are a new force in the economic tide. Although China's construction industry has bid farewell to the era of simple labor, the technical level has been greatly improved, the degree of mechanization has been improved, "high, large, fine, new" buildings emerge in an endless stream, especially great progress has been made in technological innovation in recent years, construction enterprises are still characterized by labor-intensive enterprises, high output value and low benefit, which is a typical manifestation of low technological content in the industry. Relevant national statistics show that the average output value profit margin of domestic construction enterprises has been within $4 \%$, the profit margin of listed construction enterprises in the annual report is about $2.4 \%$, and the real profit margin of construction enterprises from construction is mostly about $1 \%$. Today, technological innovation is particularly important when the country encourages and advocates technological innovation, vigorously develops green buildings, intelligent buildings, Internet + and economic globalization. Intellectual property management, which is closely related to technological innovation, brings opportunities and challenges to enterprises. Compared with other enterprises, such opportunities and challenges may be more obvious and severe. The opportunity lies in the relatively high single value of building products and the wide research and development field at the technical level. The economic benefits brought by technological progress and innovation should be considerable. The challenge is that the quality of personnel in construction enterprises is uneven, there are few high-quality talents, and there is a big gap in technology research and design ability compared with IT and other technology leading industries. Facing domestic and foreign competitors, construction enterprises with intellectual property strategy, strong technological innovation ability and core technology advantages will have comparative advantages, so as to obtain the overall competitive advantage. Such as the construction of Shanghai Nanpu Bridge, the Shanghai authorities pay invited Japanese experts to come to guide the construction with high salary, but due to the Japanese side of its unique steel structure bridge engineering installation technology intellectual property protection is not rigorous enough, a company, the project general contractor in Shanghai, "steal art" success. Only 40 days later, the Japanese experts hired by high salaries had to go home; And the company in Shanghai, which is constantly innovating, has gained a foothold in the bridge market at home and abroad with its "housekeeping skills" learned by stealing art. It has successively obtained the construction contract right of Shanghai Yangpu, Xupu, Lupu, Donghai, Wuhu Yangtze River Bridge, etc. Bridge construction has also become the core advantage of its enterprises and the most dazzling economic growth point. It can be seen from this case that as a construction enterprise, we wants to occupy the market, improve its competitiveness, maintain sustainable development and obtain the maximum profit space, but if we do not protect our core technologies (patents, achievements, construction methods, etc.) and form our own technology core cluster, we will be the same as the Japanese company at that time, our core technological advantages will gradually lose, and many of our original construction markets will be replaced by others, not to mention the realization of building "metallurgical construction national team".

\section{Current working situation of intellectual property management of construction enterprises}

According to incomplete statistics, from 2001 to 2016, more than 850000 domestic construction patents were authorized, 2542 national construction methods were publicly released, and about 3000 civil construction papers were included in major foreign search tools, showing an increasing trend year by year. However, the proportion of domestic patent applications in the same period only increased from $2.4 \%$ in 2001 to $3.2 \%$ in 2016 , it is seriously inconsistent with the contribution and status of the construction industry in the gross national product. Through these figures, we can see that the current intellectual property protection in the construction industry lags behind, which is incompatible with the rapid development of the industry. From 2001 to 2016, the author's enterprise has made great achievements in 
technological innovation and intellectual property management. It has been recognized as a technological innovation enterprise for many times. There are 2088 domestic construction patents, only 1 in 2003, 4 in 2005, 251 in 2010 and 440 in 2016. Although it is increasing year by year, accounts for $0.01 \%$ to $0.35 \%$ of domestic construction patents, and have publicly release 12 national construction methods, due to the limited quantity and quality of high-quality patents, the enterprise has not been able to form a core technology group, so it has not cultivated core technology advantages. Generally speaking, most construction enterprises have the following problems in the actual operation of intellectual property management:

\section{1. the intellectual property protection mechanism and system of the construction industry are imperfect}

At present, the construction industry lacks perfect protection mechanism and system, and the internal core technical secrets and patents of the enterprise are difficult to be effectively protected: First, the employees change jobs frequently, and the core technologies and trade secrets that the employees master or know well in the original enterprise will serve the new enterprise. Second, in the bidding process, the construction party often gives the unsuccessful scheme to the bid winner free of charge to "optimize the implementation scheme," and etc. These violations of laws and regulations on intellectual property protection have seriously disturbed the construction market, stifled the enthusiasm of enterprises to cultivate core technology advantages, and increased the difficulty of construction enterprises to implement intellectual property protection. However, such acts or practices have not been punished or effectively stopped.

\subsection{Intellectual property rights for construction enterprises}

Construction enterprises have little idea of intellectual property rights, pay insufficient attention to intellectual property rights, and have not fully realized the importance of intellectual property rights, especially patent technology, to the development of enterprises. Some people even think that innovation management is a department that spends money and does not make money. To tell the truth, on the surface, construction enterprises to protect intellectual property rights, from innovation, research and development, declaration, reward, maintenance to rights protection and so on will incur costs and expenses; At the same time, due to the low technical content in the actual construction, the application of new technology involves a wide range (owners, designers, supervisors, etc.), the promotion is difficult and the confidentiality is poor. Most construction enterprises generally adopt the practice of "take-in" and think that "take-in" is more practical and economical. However, with the progress and development of society, the improvement of domestic intellectual property legal system, and the improvement of intellectual property awareness at home and abroad, as well as from the perspective of many domestic intellectual property rights protection events (such as the case of "high-altitude spray dust suppression system" of Wuhan Cuiyu company), this "taking doctrine" view and practice is outdated and has legal risks. Therefore, construction enterprises are required to carry out independent innovation, reserve certain technical resources, and effectively protect the achievements of independent innovation. Then, construction enterprises can develop continuously and healthily.

\subsection{Patent infringement disputes are increasing}

In recent years, new inventions, new processes and new technologies developed and applied in the construction industry emerge one after another, and intellectual property lawsuits also occur from time to time. Problems, such as "piracy" of architectural design, counterfeiting of construction products, misappropriation of technical schemes in the bidding process, infringement of construction software, etc., are often due to the use of suspected patent infringing products and technologies by construction enterprises 
in construction, and there is no agreement on relevant intellectual property terms in the contract; Moreover, the entry threshold of the construction industry is low. Some enterprises survive by copying and counterfeiting other people's technologies or products, especially patented technologies. Therefore, intellectual property infringement disputes occur frequently.

\section{Counter measures of intellectual property management of construction enterprises \\ 4.1. Establish a sound intellectual property management system}

Construction enterprises should aim at the characteristics of low technical content of the industry, difficult confidentiality of construction workplaces, large number of contacts and high mobility. First of all, the enterprise should have a special management organization and formulate management measures for technology research and development, achievements, patents, construction methods, etc. according to its own characteristics, especially for special property rights protection in the process of bidding and contract signing. Secondly, the personnel mobility of construction enterprises is large. In order to ensure the confidentiality of technical achievements, it is necessary to improve the confidentiality management of personnel related to technological innovation, and promote the signing of confidentiality agreements and peer competition restrictions between enterprises and relevant personnel. Third, we should establish a sound examination and approval system for the release of technical papers and network information, so as to ensure that the core technical achievements of the enterprise are effectively protected before they are made public and prevent leaks from happening. Fourth, we should establish and implement an intellectual property evaluation system, fully evaluate the intellectual property owned by enterprises, classify management and focus on protection, reduce the maintenance cost of intellectual property, and create greater value for enterprises. Fifth, establish a reward and punishment system in combination with the characteristics of the enterprise. In order to improve the enthusiasm of enterprise employees for innovation and the awareness of intellectual property protection, reward and punishment measures should be implemented in place in time. In short, only a perfect management system can better improve the protection of intellectual property rights and the innovation vitality of enterprises.

\subsection{Equipped with a professional innovation team}

The excavation and innovation of enterprise core technology need to be completed by a professional team. Only by continuous innovation can the enterprise be in an invincible position. Research and innovate the enterprise's core technology, so as to form its own core technology group. For example, although the company of the author has more than 2,000 patented technologies, the patent distribution is relatively scattered, and our core technology group has not been formed. At present, the technological innovation is only to rely on construction site technicians part-time to complete. But the construction management tasks of site personnel is heavy, the energy used in technology innovation is not enough, related professionals is scattered, collective innovation environment is insufficient, so they innovate only because they have to in order to fulfill the innovation task assigned by their superiors, which lead to innovative technology content is also difficult to have a big breakthrough and beyond, with the lack of the core competitiveness of highquality patents. Therefore, in order to make great breakthroughs and surpass in technological innovation, form core technology group and cultivate core competitive advantages, it is necessary to equip professional innovation teams, such as specialized structural innovation team, electrical innovation team and pipe corridor innovation team, so as to increase investment in technological innovation. With the patent management system, capability improvement platform and external resource platform as the support and intellectual property strategy as the leading role, a comprehensive enterprise intellectual property management system with technological innovation, intellectual property risk control and intellectual property operation as the core shall be formed. Through the professional innovation team in-depth 
construction of the first line to guide the promotion and application of innovative technology achievements, give full play to the greater value of technological innovation.

\subsection{Improve the intellectual property competitiveness of enterprises and cultivate their core technology advantages}

To improve the intellectual property competitiveness of enterprises, we should have our own intellectual property achievements. The number of patents, patent clusters and patent technology content of an enterprise are the main embodiment of the intellectual property competitiveness of enterprises. To improve the number and technical content of patent applications, construction enterprises can start from the following aspects: First, according to the patent source channel, we can explore patents from the aspects of pioneering invention, combined invention $(1+1>2)$, selective invention, conversion invention, new use invention of known products, etc. Second, in the process of patent mining, we form our own patented technology by putting forward our goals, such as what needs to be met, what functions to be added, what performance to be improved, optimizing the structure or miniaturization, more convenient and humanized operation, reducing costs, etc. Third, we can also add new features on the basis of traditional schemes, replace some existing features with new features, or adopt a new technical scheme or combine several schemes into a new scheme, or form our own patent technology for application. Fourth, starting from the task of an overall project, first find out the components of the task, find out the innovation points of each technical element by analyzing the technical elements of each component, and finally summarize the technical scheme according to the innovation points to form your own patent. Fifth, according to the technical elements of the whole project and the construction environment, find out the technical factors that break through the environment, so as to put forward the innovation points. Finally, summarize the technical scheme according to the innovation points and apply for patents. Sixth, improve the shortcomings of previous patents, divide the working environment of the same construction object, find out other innovation points, and finally summarize the technical scheme according to the innovation points, so as to apply for patents. Seventh, boldly envisage the application of technologies that cannot be realized in our construction field in other fields, so as to achieve substantive results and apply for patents (such as applying the car door design technology to our manhole cover).

\subsection{Strengthen the promotion and application of new technologies in enterprises}

Only when the technological innovation achievements and core technologies of enterprises are applied to construction practice can they form technical advantages and maximize the transformation of achievements, which is an effective means to improve the competitiveness of enterprises. At present, the intellectual property of our enterprise mainly stays in the reserve, and there is little application and promotion, mainly because the construction technicians do not know enough about the intellectual property achievements of our enterprise. To comprehensively promote the application and industrialization of technical achievements, first, in the bidding process, we should vigorously promote the application of our proprietary technology, core patents, construction methods and achievements on the premise of effective protection, so as to improve our bid winning rate. Second, during the construction process, we should strengthen the application of our patents and construction methods, and adopt various ways to promote and study the company's patented technology, scientific and technological achievements, construction methods and other specific contents face-to-face. Third, establish the company's technological innovation network platform, divide all the company's technological achievements and technologies into disciplines, and establish a general retrieval account, so as to promote the use of technological achievements and avoid repeated research and design. Fourth, the technical innovation professional team goes deep into the construction front-line training and guidance, organizes relevant personnel, selects the technical innovation achievements related to the 
specific construction content for training, and guides the promotion of the project. Fifth, establish an indicator assessment system for the promotion and application of technological innovation achievements. Each construction project must use and promote several technological achievements. In the process of promotion, the enterprise technological innovation management department monitors the process, forms text and picture summaries on the project, and reports the completion of the indicators. New technology promotion must be realized by mandatory means.

\section{Summary}

In short, construction enterprises need to cultivate core competitiveness in order to maintain healthy and stable development. Core competitiveness comes from core technology advantages, which rely on intellectual property management. Therefore, construction enterprises should establish and improve the intellectual property management system, establish technical innovation teams of relevant disciplines, increase the application of technical innovation and technical achievements, establish a technical innovation platform, strengthen the publicity of technical innovation, popularize technical innovation knowledge, and improve the awareness and level of technical innovation, so as to reserve rich technical resources and technical achievements. At the same time, do a good job in safeguarding intellectual property rights to strive for the maximum profit space and broad construction market for enterprises.

\section{Disclosure statement}

The author declares no conflict of interest. 